\title{
The Numerical Techniques for Thermal Distribution Analysis in Optical Waveguides
}

\author{
Maslina Yaacob*, Mohd Haniff Ibrahim, Norazan Mohd Kassim and Abu Bakar Mohammad \\ Photonics Technology Centre, Faculty of Electrical Engineering, Universiti Teknologi Malaysia, 81310, Skudai, Johor, Malaysia. \\ *Author to whom correspondence should be addressed. E-mail: mas_lina2003@yahoo.com
}

Received: 11 November 2008

http://dx.doi.org/10.11113/mjfas.v4n2.48

\section{ABSTRACT}

In this paper, the analysis of thermal distribution in planar optical waveguide cross-section when a single heater electrode applied is presented. Starting from the heat equation, the thermal analysis has been done using two proposed numerical methods which are include finite difference method (FDM) and finite element method (FEM). By considering conduction as the only heat transfer mechanism, the obtained results from the mentioned methods are shown to have a good agreement.

| Thermal analysis | Finite difference method | Finite element method |

\section{Introduction}

The optical waveguides can be of various structures such the rib, strip, embedded, ridge and buried type. These structures can be further manipulated to produce passive and active waveguides based on applied external field such as heat [1]. An active waveguide which is based on heat-controlling effect is called a thermo-optic structure. Such structure has been implemented in the design of optical devices such as modulator and switch [23]. The fundamental phase in designing the thermo-optic structure is through the thermal distribution analysis. This phase is vastly required as heat distribution in the optical waveguides can be obtained and thus, proper placement of heater electrodes can be designed in order to ensure excellent performance of the optical device.

Various techniques have been adopted in the waveguide thermal distribution analysis. Such techniques are finite element method [4], finite difference method [5] and Fourier Transform method [6]. In this paper, two numerical techniques are adopted in solving differential equation for analysis of thermal distribution in a planar waveguide structure. Those techniques are finite difference method and finite element method. Further explanations of the method are provided in this paper.

The paper is arranged in five sections. Section 2 is focusing on the theoretical review of heat equation and working concepts of the technique. Methods of analyzing the temperature distribution in planar waveguide structure are presented in Section 3. Simulation results of thermal distribution and the comparison between techniques are presented in Section 4 and finally remarks conclusion in Section 5. 


\section{Theoretical Reviews}

Conduction mechanism is important primarily for heat transfer in the material such as solid and stationary fluid. It is determined by local temperature gradient that exists in the material [7]. The governing equation for heat diffusion equation for solid material is given by [7]:

$$
\rho C \frac{d T}{d t}=\nabla \cdot(k \nabla T)+\dot{Q}^{\prime \prime \prime}
$$

where

$$
\begin{aligned}
& Q^{\prime \prime \prime}=\text { distributed thermal source per unit volume }\left(\mathrm{W} / \mathrm{m}^{3}\right) \\
& \rho=\text { density of material }\left(\mathrm{kg} / \mathrm{m}^{3}\right) \\
& C=\text { specific heat }(\mathrm{J} / \mathrm{kg} \cdot \mathrm{K}) \\
& t=\text { time }(\mathrm{s}) \\
& k=\text { thermal conductivity }(\mathrm{W} / \mathrm{m} . \mathrm{K})
\end{aligned}
$$

If consideration of time is not important as being demonstrated by [8], the steady state condition for heat diffusion equation can further be simplified as follow:

$$
\nabla \cdot(k \nabla T)+\dot{Q}^{\prime \prime \prime}=0
$$

By assuming the case of conduction in long bars compared to the small dimension of waveguide cross section, equation (2) can be simplified into two dimensional (2-D) solution. By considering the $\mathrm{z}$ direction as the longitudinal direction, equation (2) can be written as:

$$
\frac{d^{2} T}{d x^{2}}+\frac{d^{2} T}{d y^{2}}+\frac{\dot{Q}^{\prime \prime \prime}}{k}=0
$$

In order to determine temperature distribution in the waveguide, we need to solve the appropriate form of the differential heat diffusion using the boundary condition. The waveguide having differential thermal conductivities, $k_{A}$ and $k_{C}$, and heat source with supply power of $P$ and width of $B$ and length of $L$ as depicted in Figure 1. follow:

By considering the conduction as the only heat transfer mechanism, the boundary condition can be stated as

Top plate with heat source interface

$$
-k_{A} \frac{d T}{d y}=\frac{P}{B L}
$$


Interface between material $\left(k_{A}\right.$ and $\left.k_{c}\right)$

$$
\begin{aligned}
& k_{A} \frac{d T}{d y}=k_{c} \frac{d T}{d y} \\
& k_{A} \frac{d T}{d x}=k_{c} \frac{d T}{d x}
\end{aligned}
$$

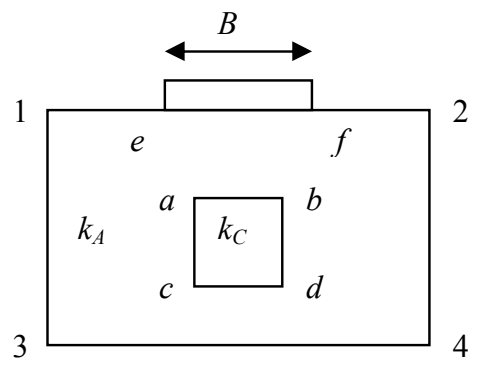

Figure 1: Waveguide cross section with heat source.

\section{Finite Difference Method}

For this method, the solution region which is representing the waveguide cross section is divided into small region or mesh of $\Delta x$ and $\Delta y$ in the $x$ and $y$ directions, respectively. The temperature, $T$ is considered to be discrete value at respective coordinate, $T(i, j)$ in solution region as depicted in Figure 2 .

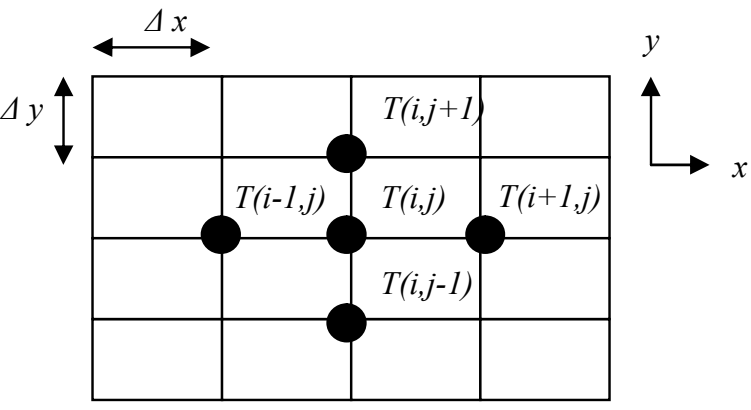

Figure 2: Division of the solution region into grid point for finite difference calculation.

The finite difference approximation for heat diffusion equation can be derived by using Taylor series method and control volume method [7]. By applying two points finite difference formulas for first derivatives to equation (4), (5) and (6) will produce a discrete formulation to determine any node at each boundary. 
The boundary condition and its finite difference approximation are presented as follow:

Top plate with heat source interface (Boundary $e-f$ )

$$
T_{(i, j)}=\frac{2 T_{i, j+1}+T_{i+1, j}+T_{i-1, j}+\frac{2 \Delta y P}{k_{A} B L}}{4}
$$

Top boundary without heat source (Boundary $1 e$ and $2 f$ )

$$
T_{(i, j)}=\frac{1}{4}\left(2 T_{i, j+1}+T_{i+1, j}+T_{i-1, j}\right)
$$

Left plates (boundary 1-3)

$$
T_{(i, j)}=\frac{1}{4}\left(2 T_{i+1, j}+T_{i, j+1}+T_{i, j-1}\right)
$$

Interface between material $\left(k_{A}\right.$ and $\left.k_{c}\right)$

(Boundary $a b$ )

$$
T_{(i, j)}=\frac{k_{C} T_{i, j+1}+k_{A} T_{i, j-1}}{k_{A}+k_{C}}
$$

(Boundary $b d$ )

$$
T_{(i, j)}=\frac{k_{C} T_{i, j+1}+k_{A} T_{i, j-1}}{k_{A}+k_{C}}
$$

where $i$ and $j$ represent the mesh point corresponding to $x$ and $y$ direction respectively.

\section{Finite Element Method}

Finite Element Method is another useful numerical technique in solving differential equation. This method suitable for the mode analysis of optical waveguide with complicated waveguide structure and arbitrary refractive index profiles [9]. In this method, the solution region is divided into finite number of element, which connected to each other at specific node as illustrated in Figure 3.

The finite element analysis involves basically four steps: (a) discretizing the solution region into a finite number of subregions or elements, (b) deriving governing equations for a typical element, (c) assembling of all elements in the solution region and (d) solving the system of equations obtained [10]. 


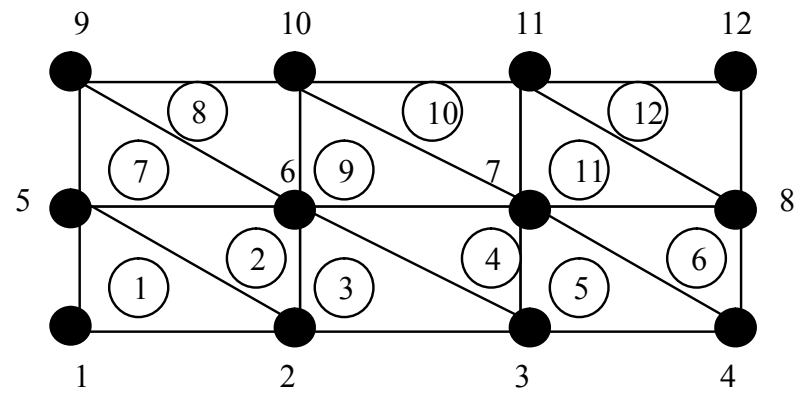

Figure 3: A finite element subdivision in solution region.

\section{Method of Analysis}

The simulation is based on the planar structure of waveguide as shown in Figure 4. The simulation was done on MATLAB ${ }^{\circledR}$ programming platform for the finite difference method and FEMLAB simulation software from COMSOLAB for the finite element method.

For the validation purposes, the initial simulation was done for the structure work by Wang et al. [6] as depicted in Figure 4. The structure consists of silica glass as the core and the cladding layer deposited on silicon (Si) substrate. A $10 \mu \mathrm{m}$ wide-thin film heater with $0.25 \mathrm{Wmm}^{-1}$ heating power is placed on top of the upper cladding. During the simulation phase, the conduction as heat transfer mechanism was the only consideration being made while ignoring the convection and radiation. The core and cladding layer are assumed to have the same thermal conductivity, $k$ and silicon substrate was assumed as perfect heat sink.

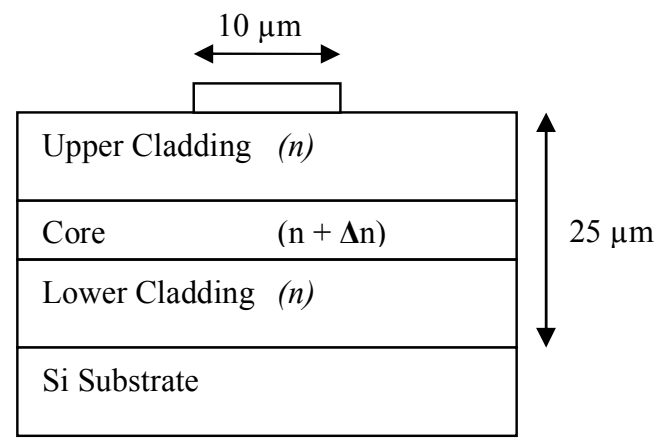

Figure 4: Cross section of structure work by Wang et al. [6].

The following parameters are taken into accounts based on work reported by Wang et al. [6]:

- $\quad$ Thermal conductivity of $\mathrm{Si}=150(\mathrm{~W} / \mathrm{m} . \mathrm{K})$

- Thermal conductivity of silica glass $=1.40(\mathrm{~W} / \mathrm{m} . \mathrm{K})$

- $\quad$ Thermal conductivity of air $=2.6 \times 10^{-2}(\mathrm{~W} / \mathrm{m} . \mathrm{K})$ 


\section{Results}

According to Wang et al. [6], the maximal temperature at the silica-glass top surface is around $160^{\circ} \mathrm{C}$ which using Fourier Transform method. In this work, the simulation results which have been done using finite different method and finite element method shows a good agreement with the result obtained by Wang et al. [6]. Thus, it can be concluded that the simulation technique used is correct and considerably accepted. The simulation results for finite difference method and finite element method are presented in Figure 5 and Figure 6, respectively.

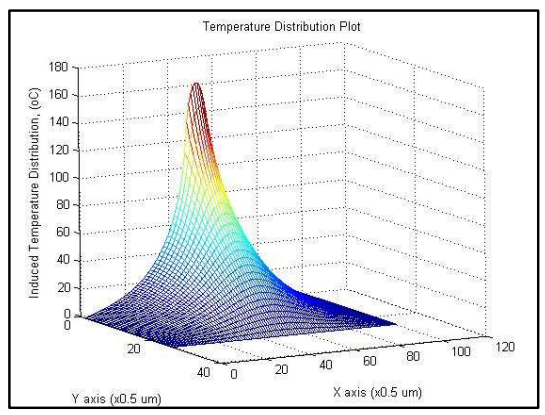

Figure 5: Temperature distribution plot using finite difference method.

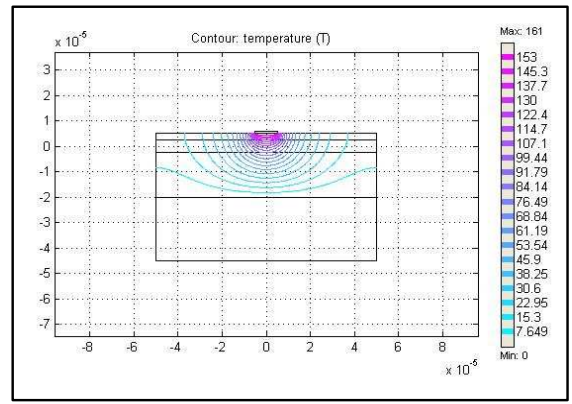

Figure 6: Contour plot for temperature distribution using finite element method.

Since the simulation technique was correct, the analysis was then carried out to investigate the effect of total thickness of silica-glass to the maximum temperature at the silica-glass top surface. This investigation was done by varying the waveguide thickness, $d$ from $25 \mu \mathrm{m}$ to $31 \mu \mathrm{m}$ as shown in Figure 7 . The analysis is important to be used in actual development of thermo-optic based optical switch devices.

The results obtained for finite difference method and finite element method are depicted in Figure 8(a) and Figure 8(b), respectively. It was clearly shown that the maximum temperature at the silica-glass top surface is increase as the total thickness of silica-glass increase. This condition occurred due to the increasing distance between heater and heat sink that further caused the reduction of thermal absorption by the heat sink. 


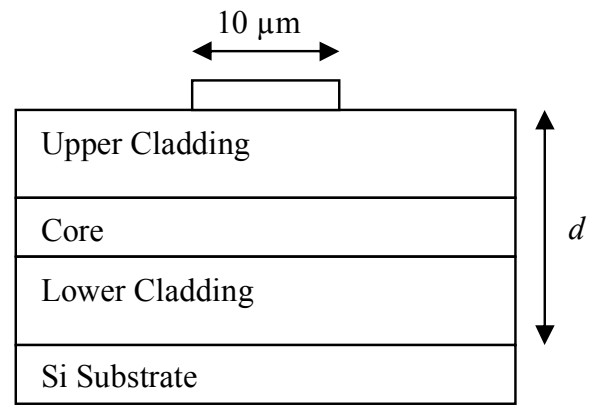

Figure 7: Waveguide cross-section with total thickness of silica glass, $d$ is varied from $25 \mu \mathrm{m}$ to $31 \mu \mathrm{m}$.

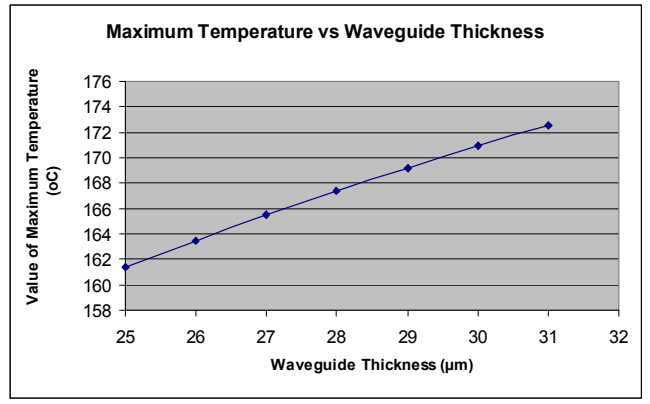

(a)

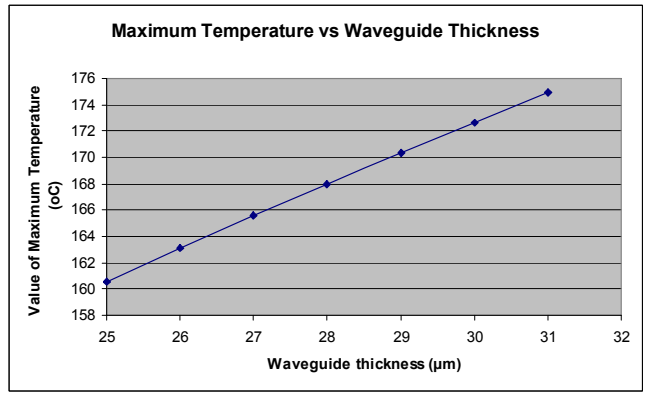

(b)

Figure 8: Result from (a) finite difference method (b) finite element method.

\section{Conclusion}

In this paper, we deal with two numerical techniques which are finite different method and finite element method for analysis of in planar waveguide structure. The temperature distributions obtained from both methods have been plotted. It can be concluded that the maximum temperature of the proposed structure shows a good agreement by using both numerical techniques. As a conclusion, either Finite Difference Method or Finite 
Element Method can be adopted in solving the thermal distribution analysis in optical waveguide. These findings will be an initial step for further research related to thermal analysis in various optical waveguides and device development, particularly an active device which requires thermal control.

\section{Acknowledgements}

The authors acknowledge the Ministry of Science, Technology and Innovation of Malaysia for the financial support through Fundamental Research Grant Scheme (FRGS) vot number 78192. This research is also supported in parts by Nippon Sheet Glass Foundation for Materials Science and Engineering through Overseas Research Grant Scheme (ORGS).

\section{References}

[1] Q. Lai, W. Hunziker, and H.Melchior, IEEE Photonics Technology Letters, (1998) Vol.10.

[2] Mart B.J. Diemeer, Optical metarial, (1998) 192-200.

[3] F.R. Akkari*, K.H. Cazzini, W. Blau, Journal of Non-Crystalline Solids, (1995) 494-497.

[4] Francisca Sircili, Macros A.R. Franco, Angelo Passaro and Nancy M. Abe, SBMO/IEE MTT-S IMOC Proceeding, (2001) 329-332

[5] Mohd Haniff Ibrahim, Norazan Mohd Kassim, Abu Bakar Mohammad \& Nazri Kamsah, Jurnal Teknologi (2007) 93-102.

[6] Weyl-kuo Wang, Hyung Jong Lee, and Philip J. Anthony, Journal of Lightwave Technology, (1996) 429436.

[7] Pradip Majumdar, Computational Methods for Heat and Mass Transfer, first ed., Taylor \& Francis, New York, 2005.

[8] Klunder, D.J.W.,Traineeship Report at IBM Zurich Research Laboratory, (1997) 20-33.

[9] Katsunari Okamoto, Fundamental of Optical Waveguides, second ed., Academic Press, USA, 2006.

[10] Matthew N. O. Sadiku, Element of Electromagnetic, third ed., Oxford University Press, New York, 2001. 